\title{
Clinicopathological Pattern of Basal Cell Carcinoma among Sudanese Patients
}

\author{
Tasneem Mohammed Elshiekh Sulieman, Nazik Elmalaika Obaid Seid Ahmed Husain* \\ Department of Pathology, Faculty of Medicine and Health Sciences, Omdurman Islamic University, Omdurman, Sudan \\ Email: tasneemelshiekh@yahoo.com, *nazikhusain@gmail.com
}

How to cite this paper: Sulieman, T.M.E. and Husain, N.E. (2017) Clinicopathological Pattern of Basal Cell Carcinoma among Sudanese Patients. Open Journal of Pathology, 7, 67-79.

https://doi.org/10.4236/ojpathology.2017.74007

Received: August 14, 2017

Accepted: September 5, 2017

Published: September 8, 2017

Copyright ( 92017 by authors and Scientific Research Publishing Inc. This work is licensed under the Creative Commons Attribution International License (CC BY 4.0).

http://creativecommons.org/licenses/by/4.0/ (c) (i) Open Access

\begin{abstract}
Background: Basal cell carcinoma (BCC) is a frequently diagnosed skin cancer with variable histopathological types. BCC was not widely studied in Sudan as it is in the Caucasian population. Objectives: To appraise the clinical and histopathological aspects of BCC of the skin in Sudan. Materials and methods: A retrospective descriptive analysis of 84 histologically diagnosed BCC specimens seen at three hospitals in four-year duration were reviewed and classified into histological variants according to the WHO classification 2006. Data were analyzed using Statistical Package for the Social Sciences, version 23.0. Results: The mean age $( \pm \mathrm{SD})$ of the study participants was $56( \pm 1.75)$ years, ranging from 20 to 92 years and $63.1 \%$ were females (Female to male ratio 1.7:1). The most common incidence was among the age group 51 - 60 years. The face was the primary tumor site in $89.3 \%$ with a predilection for the nasal area ( $31 \%$ of those in the face), followed by the trunk (6\%). Out of the total, $54.8 \%$ were histologically categorized as nodular/solid, while infiltrative accounts for $11.9 \%$ followed by the superficial type (8.3\%). Surgical margins were involved in $34.5 \%$ of cases and peri-neural invasion was seen in $3.6 \%$ of cases, mostly were of the infiltrative variant. Conclusion: BCC in Sudan is commonly present in the head as solid nodular histopathological variant which is correlated with worldwide distribution but has slightly younger age and female predominance; thus further studies are needed to assess risk factors in Sudanese patients and improve approaches for earlier diagnosis and better management.
\end{abstract}

\section{Keywords}

Basal Cell Carcinoma, Skin, Histologic Pattern, WHO Classification, Sudan 


\section{Introduction}

Basal cell carcinoma (BCC) is a commonly diagnosed skin cancer representing $70 \%$ of skin cancers and originating from the basal layer of the epidermis and its appendages [1] [2]. BCCs most commonly arise in sun exposed skin of middle-aged to elderly individuals. About ten million individuals are diagnosed annually with BCC across the globe [3]. Though BCCs cause less than $0.1 \%$ of patient mortality and have low metastatic potential, they are locally destructive to skin and surrounding structures including bone [3] [4].

The greatest proportions of skin cancer are encountered in regions with high quantities of ultra violet (UV) radiation such as South Africa and Australia [5]. Unlike squamous cell carcinoma, which accounts for $16 \%$ of skin cancers, BCC is not life threatening. Despite low mortality of BCC, it has a significant public health impact [6].

Generally, men are known to be affected twice as often as women. This could be attributed to increased work-related exposure to the sun, though these dissimilarities are becoming less significant with changes in lifestyle. The reported male to female ratio is about 2.1:1 [4].

BCC has different clinical presentations including shining papules with noticeable subepidermal blood vessels, ulcerative lesion, nodules and pigmented lesion [1]. They may be locally destructive invading bone or facial sinuses causing "rodent ulcers". The superficial BCC sometimes mimics melanoma when presents as plaques that are erythematous or pigmented. Other variants include nodular basal cell carcinoma, micronodular, infiltrating, fibroepithelial, basosquamous, keratotic and basal cell carcinoma with adnexal differentiation [6]. Nodular BCC occurs at a later age than superficial variant and more frequent on the head while the superficial tumors are commonly seen in the trunk [6]. Histological types such as cystic, adenoid, morpheaform, infundibulocystic, pigmented and various other types are very rare [2]. A recently described subtype is the red dot basal cell carcinoma which appears as a new red dot that Blanche after diascopy [7].

Although BCC is seen in people of all ethnicities and skin kinds, dark-skinned persons are rarely affected. It is most often found in light-skinned individuals, yet there are marked ethnic and geographical variability. Genetic predisposition and UV exposure are considered important predisposing factors for BCC [4] [6] [8].

In Sudan, there is difficulty in estimating incidence of BCC because it is usually not included in cancer registry statistics. There are a few published studies about it recently. BCC represented (14.9\%) of superficial skin cancers in Sudan in a remote study done on 1972 [9]. Knowledge of local data is important so as to make an early diagnosis, plan preventive actions and provide information for healthcare professionals.

This study mainly focused on clinical presentation and histopathological patterns of BCC among Sudanese population comparing it with worldwide distribution. 


\section{Materials and Methods}

\subsection{Study Design and Area}

This descriptive cross-sectional study was conducted in three main pathology centers in Khartoum State, Sudan, namely the National Health Laboratory (NHL) which a reference laboratory, Omdurman Teaching Hospital (OTH) (A tertiary hospital) and Soba University Hospital (SUH) that a tertiary hospital belongs to Khartoum University, in four years' duration (from the first of January 2010 to the 31 of December 2013).

\subsection{Study Population}

This study included all patients diagnosed histologically as basal cell carcinoma at the Histopathology Departments of (NHL), (OTH) and (SUH) during the study period with adequate records and histological slides or paraffin wax embedded blocks. Cases with deficient records missed request forms or missed histopathology slides or paraffin wax embedded blocks were excluded. All BCC cases diagnosed histologically in the three study areas during the study period were potential subjects to be included in this study (97 cases). Eighty-four of them fulfilled the inclusion criteria.

\subsection{Data Collection Tool}

A predesigned questionnaire was filled by the first author. Variable includes age, gender, site, margins, histological variants and clinical information.

\subsection{Methodology}

From paraffin embedded blocks thin histological sections were obtained and stained with Hematoxylin and eosin (H \& E) stain, then examined under light microscopy by the two authors. BCC cases were classified into histological variants according to WHO classification 2006 [10].

\subsection{Data Analysis}

The collected data were analyzed by Statistical Package for the Social Sciences (SPSS) (IBM, USA) analytical system version 23.0. Descriptive statistics and Chi squire test were used. $P$ value at less than 0.05 was considered significant.

\subsection{Ethical Considerations}

The study was approved by the Ethics Committee of MD Pathology-Khartoum University. Permission to conduct the study was taken from the directors of the three study areas.

\section{Results}

\subsection{Sociodemographic Characteristics}

During the four years of the study period, the total number of cases diagnosed as 
basal cell carcinoma in the three centers was 97 cases, of which 13 cases were excluded. Eighty-four cases were included in this study.

In this study, the age of patients ranged from 20 to 92 years with a mean age $( \pm S D)$ of $56( \pm 1.75)$ years. The most common incidence was among the age group 51 - 60 years $40(46.4 \%)$ and $13(15.5 \%)$ were $>70$ years.

Regarding gender distribution 53 cases $(63.1 \%)$ were females and 31 cases (36.9\%) were males with a female to male ratio 1.7:1.

Total percentage of females $<50$ years was $21(39.6 \%)$ while males in this age group were $10(32.3 \%)$ (Table 1$)$.

\subsection{Primary Sites Involved with BCC in the Study Group}

Distribution of primary sites involved is shown in (Figure 1). Most cases were seen in the face (89.3\%), particularly the nose comprising (31\%) of those in the face, followed by trunk (6\%). Other sites including the and lower limbs represents (4.8\%).

a

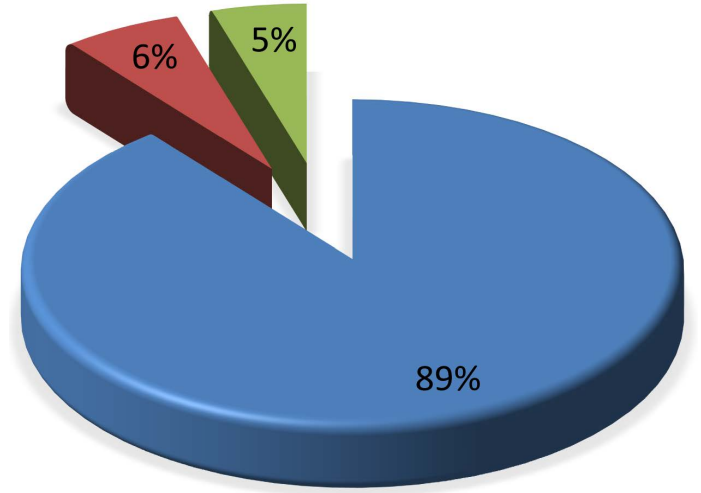

Figure 1. Distribution of the study population according to the site of BCC.

Table 1. Distribution of studied basal cell carcinoma patients according to age group and gender.

\begin{tabular}{cccc}
\hline & \multicolumn{3}{c}{ Gender } \\
\cline { 2 - 4 } Age Groups & Male & Female & Total \\
& \% Count within gender & \% Count within gender & \% Count within gender \\
\hline \multirow{2}{*}{$20-50$} & 10 & 21 & 31 \\
& $32.3 \%$ & $39.6 \%$ & $36.9 \%$ \\
& 15 & & 40 \\
& $48.4 \%$ & 25 & $47.6 \%$ \\
& 6 & $47.2 \%$ & 13 \\
Total & $19.4 \%$ & 7 & $15.5 \%$ \\
& 31 & $13.2 \%$ & 84 \\
& $100.0 \%$ & 53 & $100.0 \%$ \\
\hline
\end{tabular}




\subsection{Histopathological Variants of BCC in Sudanese Patients}

Concerning histopathological variants (Figure 2), (54.8\%) were nodular variant (Figure 3(a) and Figure 3(b)) while infiltrative (Figure 3(c)) represents $(11.9 \%)$, followed by superficial variant (Figure $3(\mathrm{~d}))(8.3 \%)$ and other variants constitute lesser frequencies (Figure 3(e) and Figure 3(f)).

The histological characteristics of basal cell carcinoma; the peripheral palisading (Figure 3(a)) and stromal artifact (Figure 3(b)), are seen in the nodular pattern.

Distribution of different histological variants among body sites although statistically insignificant ( $P$-value 0.08 ) shows that the superficial variant $(33.3 \%)$, infundibulocystic (25\%) and basosquamous (75\%) mainly located in the trunk, while in the face all the variants were represented.

\subsection{Histologic Characteristics of BCC among the Studied Group}

About one third of basal cell carcinoma cases were histologically pigmented while $64.3 \%$ did not show obvious pigmentation.

The margin was involved in $34.5 \%$ while it was free in about $36.9 \%$ of the cases. Variable histological variants show difference regarding margin involvement although insignificant $(P$-value $=0.23$ ); it represented $32 \%$ of nodular solid, $55.6 \%$ of infiltrative, $50 \%$ of morpheaform, $50 \%$ of basosquamous and $100 \%$ of the micronodular variant. The peri-neural invasion was seen in $3.6 \%$ of cases, mostly were of the infiltrative variant. Regarding clinical information $4.8 \%$ of cases show the history of recurrence and 2.4\% were known cases of Albinism. One case (1.2\%) was clinically diagnosed as Xeroderma pigmentosa.

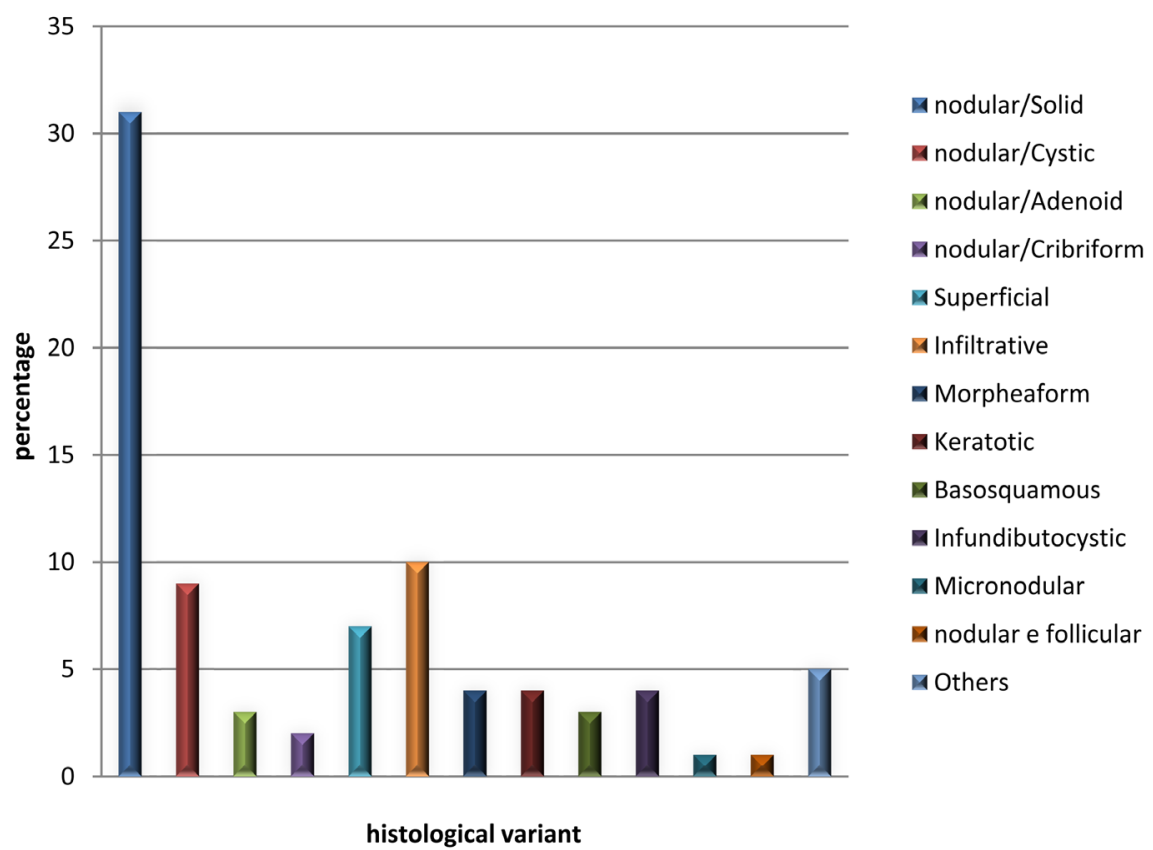

Figure 2. Histological variants of BCC among the study population. 


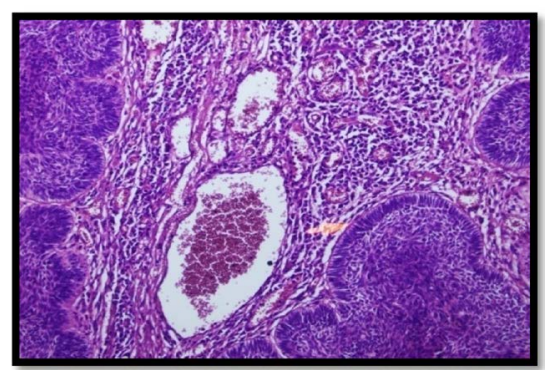

(a)

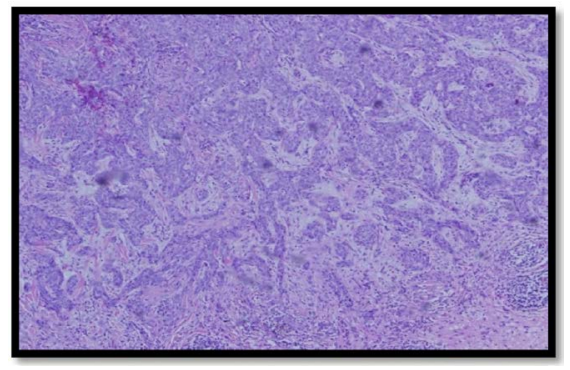

(c)

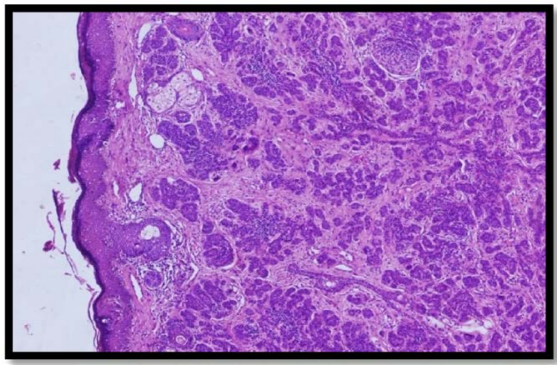

(e)

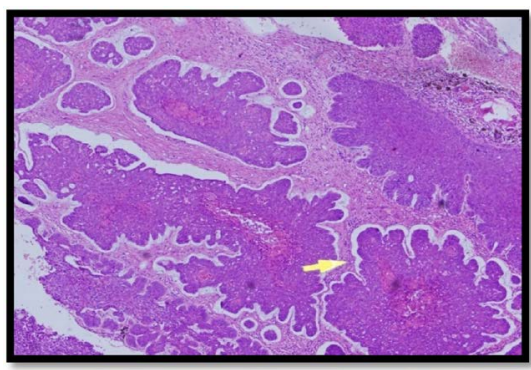

(b)

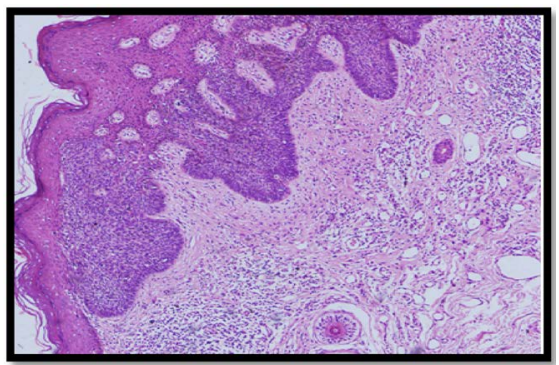

(d)

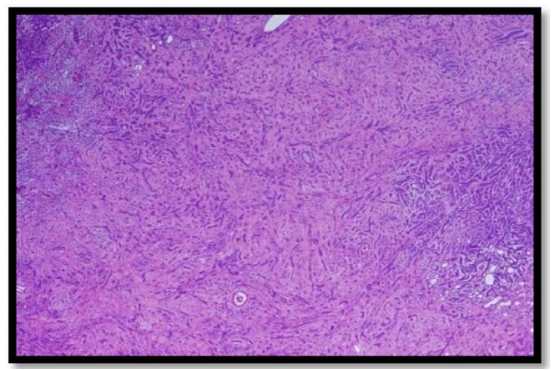

(f)

Figure 3. Histological variants of basal cell carcinoma (BCC). (a) Solid nodular variant with peripheral palisading (red arrow) (Hematoxylin and Eosin stain (H \& E), 200×); (b) Solid nodular variant with peri-tumoral clefting (yellow arrow) (H \& E, 200x); (c) Infiltrative variant (H \& E, 40x); (d) Superficial variant (H \& E, 40×); (e) Micronodular BCC (H \& E, 40×); (f) Morpheaform BCC (H \& E, 40×).

\section{Discussion}

Basal cell carcinoma is the most frequently diagnosed skin cancer globally [11] [12] [13] [14], but various studies from Africa [15] [16] [17] and Sudan [9] [18] have reported squamous cell carcinoma as the most prevalent skin cancer followed by basal cell carcinoma.

In the present study nearly $37 \%$ of all reported cases are below 50 years and the mean age is 56 years indicating that basal cell carcinoma tends to appear in younger age than what is reported in the literature when comparing it with other studies in Sudan, Egypt, Tunisia, Nigeria, South Africa and worldwide studies in Europe and USA [6] [11] [15] [16] [17] [18]. However, Deady et al. shows that there is a significant increase in BCC incidence in younger populations [19]. This decrease in age at presentation may be spurious owing to the norm that Sudanese women, who represent the majority of the study group, tend to not 
telling their true age or even they may not know it at all.

The frequency of basal cell carcinoma in men and women is different with a female preponderance in this study, unlike other studies which show male predominance [6] [20]. Nevertheless, it goes with that there is greatest increase noted in women under 40 years worldwide [21]. This could reflect the change in women lifestyle, increase in time exposure to UV and increase in outdoor activities [20] [21].

Basal cell carcinoma occurs mainly in the sun exposed regions predominantly involving the face. The majority $(89.3 \%)$ of cases were excised from the face in this study with the nose comprising $(31 \%)$ of those in the face. Other sites include the trunk $(6 \%)$ and lower limbs (4.8\%). This is comparable to what was reported in the literature [22] [23]. It was found that the basosquamous variant (75\%) and superficial (33.3\%) are mainly located on the trunk followed by infundibulocystic (25\%). Other variants occur dominantly on the head and neck. This difference regarding body distribution of BCC subtypes may reflect differences in the aetiology and predisposing factors. This was supported by other studies comparing superficial BCC cases with other variants regarding mean age, gender, and tumor site concluding that the majority of superficial BCCs occurred on the trunk and lower limbs and mean age was lower than that for other subtypes [22] [24] [25].

The most common histopathological pattern in this study was the nodular/ solid variant which is correlated with worldwide distribution, while infiltrative represents $11.9 \%$, followed by superficial variant $(8.3 \%)$ and other variants constitute lesser frequencies. This is comparable to published studies, one in the British Journal of Dermatology showing $78.7 \%$ of cases were nodular, $15.1 \%$ were superficial and 6.2\% were morpheaform [24] [26].

Many studies classify BCC as a low risk group and high risk according to biologic behavior that is to say; local recurrence, local destruction and peri-neural invasion [1]. Low risk involves nodular variant while high risk involves infiltrative, superficial and micronodular variants [22] [23] [24]. Therefore, classification of BCC according to the histopathological pattern is important to predict the behavior and thus treat accordingly [1]. Basal cell carcinoma is usually a slow-growing tumor. Some variants of BCC, such as infundibulocystic BCC, tend to be indolent, with limited potential for tissue destruction over many years. Other so-called "aggressive" variants, which include infiltrating, morpheaform, and micronodular BCCs, may cause severe tissue destruction. The vast majority of superficial and nodular BCCs are cured by excision. Narrow excisions suffice. There is no need for wide margins. For early superficial lesions, local destructive modalities, such as cryotherapy, may be adequate [27] [28] [29].

The BCC subgroup of the European Dermatology Forum (EDF)'s Guidelines Committee recognized three major clinical types of BCC (nodular, superficial and morpheaform), four histological subtypes (superficial, nodular, infiltrative and morpheaform), three prognosis groups (high, intermediate and low risk) 
and proposed therapeutic strategies that guide dermatologist for better individualized management of BCC [30].

Knowledge of site and margin involvement drives management. For facial lesions, "Mohs" surgery is the treatment of choice. Margin assessment whether with frozen or permanent sections is critical for large and infiltrative lesions. Radiation therapy is also an option for patients reluctant or unable to undergo surgery or in the case of positive margins or extensive peri-neural invasion [31] [32] [33]. In very rare cases, usually after repeated local recurrences, large and deeply infiltrative BCCs may metastasize to lymph nodes or distant sites, such as the lung, and become lethal [34] [35] [36]. However, the aggressive basosquamous variant tends to metastasize early [37].

In this study, the peri-neural invasion was associated with aggressive histopathological variants mainly the infiltrative pattern (3.6\%); a finding that is comparable with other studies [38]. Surgical margins were involved in $34.5 \%$ of cases and may be correlated with an increase in recurrence rate $(4.85 \%)$ in keeping with what has been shown in other studies [39] [40]. Margins are involved in $32.5 \%$ of the nodular solid variant, $55.5 \%$ of the infiltrative variant and $50 \%$ of morpheaform and basosquamous variants and $100 \%$ of the micronodular variant in the current study. Interestingly, the presence of single cells distant from the main tumor may contribute to the high recurrence rate in morpheaform BCC. Therefore, the use of immunohistochemical studies for $\mathrm{p} 63$ or cytokeratins is recommended when assessing margins for morpheaform BCC [41].

For reporting of biopsies, the essential task for the pathologist is to diagnose the presence or absence of a BCC. However, some clinicians may request subtyping of BCC. Knowledge of the subtype may be helpful, for example, for a "Mohs" surgeon to have a visual image of what to expect on frozen sections, especially if the slides of the prior biopsy are available. On shave or cauterization excisions, it is also helpful to comment on the margin status. Otherwise, patients with a small BCC may undergo unnecessary subsequent excisions for tumors which were already completely removed by the initial biopsy [42]. For an excision of a large BCC, in addition to the diagnosis and margin status, it also seems prudent to report the size of the lesion, to indicate which anatomic levels are involved (dermis only, subcutis, muscle, or bone), and document the histological patterns, the presence of perineural invasion and/or squamous differentiation and higher degree of cytological atypia [42].

In the current study, about $35.7 \%$ of cases were pigmented while $64.3 \%$ did not show obvious pigmentation. Some studies show that microscopic presence of melanin could be present in clinically pigmented and non-pigmented BCC [43].

Basal cell carcinoma is correlated with certain inheritance or familial diseases and this occurs in a younger age group [44] [45]. In this study, one case was clinically diagnosed as Xeroderma pigmentosa and two cases were albinos. They were linked to multiple sites and recurrence as in other studies [46]. The com- 
mon sporadic form of BCC is linked to malfunctioning of PTCH (a cell-surface transmembrane protein called Patched) signaling pathway genes, as recognized by the inactivation of PTCH and the presence of smoothened (SMO)-a G-protein-coupled receptor that transduces hedgehog $(\mathrm{Hh})$ signaling in these skin tumors [47]. PTCH mutations are reported in approximately (30\%) of sporadic BCCs, and of these about one third have mutations ( $C \rightarrow T$ transitions) that are considered hallmarks of UV damage [46] [48]. Furthermore, mutations in p53 occur in $40 \%$ to $60 \%$ of BCCs, and $60 \%$ of them have "UV signature" [46]. Xeroderma pigmentosum, a syndrome in which DNA repair is disordered, is a good example of the association between sun exposure and disorders in PTCH and p53 [47]. In these tumors, the incidence of PTCH and p53 mutations are, $90 \%$ and $40 \%$, respectively, and the majority of these show the UV signature [46] [47]. Knowledge of the genetic abnormalities of BCC is useful in developing targeted therapies. A recently published study proved the safety of the antibodies against nfP2X7 (BIL010t) which a variant of P2X7 (an ATP-gated calcium channel that accelerates proliferation and invasiveness of malignant cells) as a topical treatment for BCC [49].

One of the limitations of this study is that supplementary studies such as immunohistochemistry and molecular techniques were not used to confirm the diagnosis of these BCCs. Though the histological diagnosis of BCC is usually straightforward, however, problems can arise from histological overlap with other basaloid epithelial neoplasm and from insufficient histological sampling [50].

Basal cell carcinomas may collide with a number of epithelial and nonepithelial tumors. Common associations include BCC and seborrheic keratosis or BCC and melanocytic nevus. Immunohistochemistry may occasionally be helpful to differentiate BCC from histological mimics thereof. Basal cell carcinomas are typically immunoreactive for 34BE12, MNF116, and Berep4 which are epithelial markers. They are usually negative with Cam5.2, AE1: AE3, EMA and cytokeratin (CK)7 [50]. CK17 is diffusely expressed in BCC [51].

Focal labeling with AE1: AE3 may be seen in the squamatized portion of a BCC. Immunoreactivity with Cam5.2 or anti-CK7 may be found when eccrine ducts are entrapped by BCC or in BCCs with focal eccrine differentiation. Basal cell carcinomas are negative for CK20, but a subset of BCCs is (usually only weakly) positive for chromogranin and/or synaptophysin [50]. BCCs more than $5 \mathrm{~cm}$ in diameter were found to express neuroactive factors such as serotonin and adrenocorticotropic hormone [52].

\section{Conclusion}

BCC in Sudan is commonly present in the head as solid nodular histopathological variant which is correlated with worldwide distribution but has slightly younger age and female predominance. We noticed that peri-neural invasion is associated with aggressive histopathological variant mainly the infiltrative pat- 
tern. Different histopathological types of basal cell carcinoma are important to be included in the report because it reflects variable biological behavior. The clinicopathological correlation and professional assessment of BCC to improve approaches for earlier diagnosis and management are recommended. Further researches regarding BCC and its predisposing factors in Sudan are recommended.

\section{Acknowledgements}

Thanks to all the working staff at the National Health Laboratory, Omdurman Teaching Hospital and Soba University Hospital for facilitating the conduct of this study.

\section{References}

[1] Murkey, N., Murkey, P., Kalele, K.P. and Patil, K.P. (2017) Adenoid Variant of Basal Cell Carcinoma: A Case Report with a Glance at Biological Behavior of the Tumor. Indian Journal of Dermatology, 62, 103-105. https://doi.org/10.4103/0019-5154.198053

[2] Saxena, K., Manohar, V., Bhakhar, V. and Bahl, S. (2016) Adenoid Basal Cell Carcinoma: A Rare Facet of Basal Cell Carcinoma. BMJ Case Reports, 2016, Article ID: 10 1136/bcr-2015-214166.

[3] Copeland, G., et al. (2009) Cancer in North America: 2002-2006. Volume Three: Registry-Specific Cancer Mortality in the United States. North American Association of Central Cancer Registries Inc., Springfield.

[4] Lomas, A., Leonardi-Bee, J. and Bath-Hextall, F. (2012) A Systematic Review of Worldwide Incidence of Nonmelanoma Skin Cancer. The British Journal of Dermatology, 166, 1069-1080. https://doi.org/10.1111/j.1365-2133.2012.10830.x

[5] Raasch, B.A. and Buettner, P.G. (2002) Multiple Nonmelanoma Skin Cancer in an Exposed Australian Population. International Journal of Dermatology, 41, 652-658. https://doi.org/10.1046/j.1365-4362.2002.01573.x

[6] Rubin, A.I., Chen, E.H. and Ratner, D. (2005) Basal-Cell Carcinoma. The New England Journal of Medicine, 353, 2262-2269. https://doi.org/10.1056/NEJMra044151

[7] Cohen, P.R. (2017) Red Dot Basal Cell Carcinoma: Report of Cases and Review of This Unique Presentation of Basal Cell Carcinoma. Cureus, 9, e1110. https://doi.org/10.7759/cureus.1110

[8] Kaskel, P., et al. (2015) Ultraviolet Exposure and Risk of Melanoma and Basal Cell Carcinoma in Ulm and Dresden, Germany. Journal of the European Academy of Dermatology and Venereology: JEADV, 29, 134-142. https://doi.org/10.1111/jdv.12488

[9] Malik, M.O., Hidaytalla, A., Daoud, E.H. and El-Hassan, A.M. (1974) Superficial Cancer in the Sudan. A Study of 1225 Primary Malignant Superficial Tumours. British Journal of Cancer, 30, 355-364. https://doi.org/10.1038/bjc.1974.205

[10] Wehner, M.R., et al. (2012) Indoor Tanning and Non-Melanoma Skin Cancer: Systematic Review and Meta-Analysis. Bmj, 345, e5909. https://doi.org/10.1136/bmj.e5909

[11] Leiter, U., Eigentler, T. and Garbe, C. (2014) Epidemiology of Skin Cancer. Advances in Experimental Medicine and Biology, 810, 120-140. 
https://doi.org/10.1007/978-1-4939-0437-2_7

[12] Lipozencic, J., et al. (2010) Skin Cancers in Croatia, 2003-2005: Epidemiological Study. Collegium Antropologicum, 34, 865-869.

[13] Kim, H.S., et al. (2010) Recent Trend in the Incidence of Premalignant and Malignant Skin Lesions in Korea between 1991 and 2006. Journal of Korean Medical Science, 25, 924-929. https://doi.org/10.3346/jkms.2010.25.6.924

[14] Gloster, H.M. and Neal, K. (2006) Skin Cancer in Skin of Color. Journal of the American Academy of Dermatology, 55, 741-760.

[15] Hussein, M.R. (2005) Skin Cancer in Egypt: A Word in Your Ear. Cancer Biology and Therapy, 4, 593-595. https://doi.org/10.4161/cbt.4.5.1730

[16] Norval, M., Kellett, P. and Wright, C.Y. (2014) The Incidence and Body Site of Skin Cancers in the Population Groups of South Africa. Photodermatology, Photoimmunology and Photomedicine, 30, 262-265. https://doi.org/10.1111/phpp.12106

[17] Mseddi, M., et al. (2007) [Epidemio-Clinical Profile of Skin Cancer in Southern Tunisia]. La Tunisie Medicale, 85, 505-508.

[18] Mohamed, A.A., Mahmuod, S.M., Hassan, M.A., Haj, M.O. and Elnour, K.E.M.H. (2012) Skin Cancer in Dark Skin: A Review of 535 Patients from Sudan. Journal of Advanced Management Science, 2, 8-12.

[19] Deady, S., Sharp, L. and Comber, H. (2014) Increasing Skin Cancer Incidence in Young, Affluent, Urban Populations: A Challenge for Prevention. The British Journal of Dermatology, 171, 324-331. https://doi.org/10.1111/bjd.12988

[20] Wu, S., Han, J., Li, W.Q., Li, T. and Qureshi, A.A. (2013) Basal-Cell Carcinoma Incidence and Associated Risk Factors in U.S. Women and Men. American Journal of Epidemiology, 178, 890-897. https://doi.org/10.1093/aje/kwt073

[21] Evans, S.S., Jih, M.H., Goldberg, L.H. and Kimyai-Asadi, A. (2014) Increased Burden of Melanoma and Nonmelanoma Skin Cancer in Young Women. Dermatologic Surgery: Official Publication for American Society for Dermatologic Surgery, 40, 1385-1389.

[22] Betti, R., Inselvini, E., Carducci, M. and Crosti, C. (1995) Age and Site Prevalence OE Histologic Subtypes OE Basal Cell Carcinomas. International Journal of Dermatology, 34, 174-176. https://doi.org/10.1111/j.1365-4362.1995.tb01561.x

[23] Vantuchova, Y. and Curik, R. (2006) Histological Types of Basal Cell Carcinoma. Scripta Medica, 79, 261-270.

[24] Scrivener, Y., Grosshans, E. and Cribier, B. (2002) Variations of Basal Cell Carcinomas According to Gender, Age, Location and Histopathological Subtype. The British Journal of Dermatology, 147, 41-47.

https://doi.org/10.1046/j.1365-2133.2002.04804.x

[25] Rippey, J.J. (1998) Why Classify basal Cell Carcinomas? Histopathology, 32, 393-398.

[26] Dourmishev, L.A., Rusinova, D. and Botev, I. (2013) Clinical Variants, Stages, and Management of Basal Cell Carcinoma. Indian Dermatology Online Journal, 4, 12-17. https://doi.org/10.4103/2229-5178.105456

[27] Dandurand, M., Petit, T., Martel, P., Guillot, B. and Anaes (2006) Management of Basal Cell Carcinoma in Adults Clinical Practice Guidelines. European Journal of Dermatology: EJD, 16, 394-401.

[28] Barry, J., Oon, S.F., Watson, R. and Barnes, L. (2006) The Management of Basal Cell Carcinomas. Irish Medical Journal, 99, 179-181. 
[29] Marmur, E.S., Schmults, C.D. and Goldberg, D.J. (2004) A Review of Laser and Photodynamic Therapy for the Treatment of Nonmelanoma Skin Cancer. Dermatologic Surgery. Official Publication for American Society for Dermatologic Surgery, 30, 264-271.

[30] Trakatelli, M., et al. (2014) Update of the European Guidelines for Basal Cell Carcinoma Management. European Journal of Dermatology. EJD, 24, 312-329.

[31] Mendenhall, W.M., Amdur, R.J., Hinerman, R.W., Cognetta, A.B. and Mendenhall, N.P. (2009) Radiotherapy for Cutaneous Squamous and Basal Cell Carcinomas of the Head and Neck. The Laryngoscope, 119, 1994-1999. https://doi.org/10.1002/lary.20608

[32] Xiong, M.Y., Korgavkar, K., Digiovanna, J.J., Weinstock, M.A. and Veterans Affairs Topical Tretinoin Chemoprevention Trial Group (2014) Fluorouracil and Other Predictors of Morpheaform Basal Cell Carcinoma among High-Risk Patients: The Veterans Affairs Topical Tretinoin Chemoprevention Trial. JAMA Dermatology, 150, 332-334. https://doi.org/10.1001/jamadermatol.2013.5619

[33] Kropp, L., et al. (2013) Mohs Resection and Postoperative Radiotherapy for Head and Neck Cancers with Incidental Perineural Invasion. American Journal of Otolaryngology, 34, 373-377.

[34] McCusker, M., et al. (2014) Metastatic Basal Cell Carcinoma: Prognosis Dependent on Anatomic Site and Spread of Disease. European Journal of Cancer, 50, 774-783.

[35] Black, E.A., Duncan, L.D. and Dieter, R.A. (2013) Pulmonary Metastasis of Basal Cell Carcinoma. The American Surgeon, 79, E221-E222.

[36] Di Lernia, V., Ricci, C., Zalaudek, I. and Argenziano, G. (2013) Metastasizing Basal Cell Carcinoma. Cutis, 92, 244-246.

[37] Bucci, T., et al. (2016) Metastatic Basosquamous Carcinoma: Report of Two Cases and Clinicopathological Considerations. International Journal of Surgical Pathology, 24, 726-732. https://doi.org/10.1177/1066896916651493

[38] Leffell, D.J., Headington, J.T., Wong, D.S. and Swanson, N.A. (1991) Aggressive-Growth Basal Cell Carcinoma in Young Adults. Archives of Dermatology, 127, 1663-1667. https://doi.org/10.1001/archderm.1991.01680100063005

[39] Hamid, O. and Goldenberg, G. (2013) Identifying Patients at Risk for Recurrent or Advanced BCC. Journal of Drugs in Dermatology: JDD, 12, 1246-1252.

[40] Gudi, V., et al. (2006) Management of Basal Cell Carcinoma by Surveyed Dermatologists in Scotland. Clinical and Experimental Dermatology, 31, 648-652. https://doi.org/10.1111/j.1365-2230.2006.02199.x

[41] East, E., et al. (2016) Morpheaform Basal Cell Carcinomas with Areas of Predominantly Single-Cell Pattern of Infiltration: Diagnostic Utility of p63 and Cytokeratin. The American Journal of Dermatopathology, 38, 744-750. https://doi.org/10.1097/DAD.0000000000000541

[42] Slater, D. and McKee, P. (2002) Minimum Dataset for the Histopathological Reporting of Common Skin Cancers. The Royal College of Pathologists, London, 1-23.

[43] Tan, W.P., Tan, A.W., Ee, H.L., Kumarasinghe, P. and Tan, S.H. (2008) Melanization in Basal Cell Carcinomas: Microscopic Characterization of Clinically Pigmented and Non-Pigmented Tumours. The Australasian Journal of Dermatology, 49, 202-206. https://doi.org/10.1111/j.1440-0960.2008.00469.x

[44] Mirowski, G.W., Liu, A.A., Parks, E.T. and Caldemeyer, K.S. (2000) Nevoid Basal Cell Carcinoma Syndrome. Journal of the American Academy of Dermatology, 43, 1092-1109. https://doi.org/10.1067/mjd.2000.107944 
[45] Nilsson, M., et al. (2000) Induction of Basal Cell Carcinomas and Trichoepitheliomas in Mice Overexpressing GLI-1. Proceedings of the National Academy of Sciences of the United States of America, 97, 3438-3443. https://doi.org/10.1073/pnas.97.7.3438

[46] D’Errico, M., et al. (2000) UV Mutation Signature in Tumor Suppressor Genes Involved in Skin Carcinogenesis in Xeroderma Pigmentosum Patients. Oncogene, 19, 463-467.

[47] Kim, M.Y., Park, H.J., Baek, S.C., Byun, D.G. and Houh, D. (2002) Mutations of the p53 and PTCH Gene in Basal Cell Carcinomas: UV Mutation Signature and Strand Bias. Journal of Dermatological Science, 29, 1-9.

[48] Hahn, H., et al. (1996) Mutations of the Human Homolog of Drosophila Patched in the Nevoid Basal Cell Carcinoma Syndrome. Cell, 85, 841-851.

[49] Gilbert, S.M., et al. (2017) A Phase I Clinical Trial Demonstrates That nfP2X7 Targeted Antibodies Provide a Novel, Safe and Tolerable Topical Therapy for Basal Cell Carcinoma. The British Journal of Dermatology, 177, 117-124.

https://doi.org/10.1111/bjd.15364

[50] Busam, K.J. (2010) Dermatopathology. Elsevier Health Sciences.

[51] Goyal, A., et al. (2016) Cytokeratin 17 Is Highly Sensitive in Discriminating Cutaneous Lymphadenoma (a Distinct Trichoblastoma Variant) from Basal Cell Carcinoma. Journal of Cutaneous Pathology, 43, 422-429.

https://doi.org/10.1111/cup.12700

[52] Abyaneh, M.-A.Y., et al. (2017) Giant Basal Cell Carcinomas Express Neuroactive Mediators and Show a High Growth Rate: A Case-Control Study and Meta-Analysis of Etiopathogenic and Prognostic Factors. The American Journal of Dermatopathology, 39, 189-194. https://doi.org/10.1097/DAD.0000000000000640 